\title{
LEARNING MOTIVATION AS THE BASIC NEEDS IN IMPROVING ENGLISH SKILLS FOR NON- EFL LEARNERS COOPERATIVELY
}

\author{
Asti Gumartifa ${ }^{1}$, Betri Sirajuddin ${ }^{2}$ \\ Universitas Muhammadiyah Palembang \\ ${ }^{1}$ asti_gumartifa@um-palembang.ac.id, ${ }^{2}$ betri.sirajuddin@gmail.com
}

\begin{abstract}
The language of English has been used for many years before. The importance of the English language used has been considered by many students in school activities. Unfortunately, some students cannot master English language skills easily. There are some students' perception about the difficulties of learning English; some of them are students who have the low spirit of English learning process. English learning motivation is one of the fundamental requirements in the process of learning effectively. Motivation in learning English is a part of intrinsic factors from the students. Students have high and deep motivation in learning will gain the objective of learning well. Therefore, both teachers and students must keep improving the learning motivation to the students in the process of learning English both inside and outside of the class. This paper examines current views and scientific proof about the nature of learning motivation in improving non-English foreign language learners. This study is widely used to generate the diverse interests of teachers to the importance of motivation used in the process of English learning, especially for non-native English learners.
\end{abstract}

Keywords: English Language, English Learners, Learning Motivation, Cooperatively

\section{INTRODUCTION}

As a foreign language, learning English is a relatively complicated method. In most other words, English learners not only need to learn their language, but also each aspect of language skill. There are indeed some aspects that affect the overall performance of English learners, such as learners' motivation, understanding, inspiration, competence, family background, and so on. Among these variables, it has also been said by the English students that motivation is an important factor to support their activities in learning English. The function of learners' motivation is to master a second language also has been investigated by (Yulistianti, 2016).

Building motivation in learning English is a must. Besides, learning motivation is not eventually considered by learners only, but teachers' ways of developing students' motivation are also needed. According to Masyhur (2016), some studies examined the achievement of learners primarily is from the learning motivation aspect. These have been as a result over the last four decades that an improvement in language learning has been substantial and effect on the performance of EFL learning both inside the class and outside the class. English language learning is very needed by every single category of learners' ages and it requires some methods or strategies by those English Foreign Learners.

There seem to be children and adult English learners, who are youthful and unique that require some creative ways of inspiring learners to learn English well. As an instructor at a high school and even elementary school, they have to develop the interest of children in learning English to a certain degree. Therefore, the teacher or instructor must be accountable for students' results 
and weaknesses of learning English. When students are motivated in learning English can encourage students to learn English continuously without burden and laziness. Those who need to include the essential features for enhancing the performance of the students' motivation. Motivation certainly considers the influence of students' eagerness like the right focus, difficulty, duty, chance of learning English.

These language classrooms face some problems for the students and teachers. It is also supported by Hanafi Syahrozi, Dewi Rochsantiningsih (2018). Language classrooms created the views of students and teachers on the issues that impede the progress of students in discussing engagingly, thinking critically in the target language. Besides, motivation also has been characterized in several ways to decrease the obstacles of learning English (Bahous, Bacha, and Nabhani, 2011). He also said that given the significance assigned to the second and foreign language, teachers also encounter obstacles dealing with English at various levels of degree. Therefore, this research simply points to the efficient implementation of English learning motivation that enables students to improve skills in the English language. In this article, the author introduces studying a second language with English foreign language learners, children's learning motivation, and motivation in context.

\section{METHOD}

This research employed descriptive qualitative that utilizing library research methodology. Final result information in the form remarks or examines descriptively into online text. The data of English learning motivation, dominantly based on students' learning English motivation that is classified into some categories, students' beneficial in learning English. Information gathered was descriptive, reviewed, and represented comprehensively.

\section{RESULTS AND DISCUSSION}

\section{Results}

\section{EFL Learners in Indonesia}

Indonesian learners mean English as a foreign language. It needs many ways and practices to learn English. Some perceptions also stated by Kung (2017) that non-native English speakers can speak English easily if the English language is practiced in daily social culture. Speaking English continuously can impact people to speak English fluently. According to Parker (1979), the socio-cultural study integrates different types of mental experience, concentration, and mechanisms of memory in the perception domain. He also implied that the embraces of the behavior system concept as part of his theory of socio-culture that reflects how brains develop for learning to achieve. Therefore, the reasons for learners will be further indicated to play a crucial role in the learning process for attaining their objectives.

According to Mahadi and Jafari (2012) that students start to communicate the language from this inductive construct of accurate vocabulary by the mistakes they make and the details they receive from the factual input. Learners can also independently discover the target language, attempting to make the learning process more effective and successful. Given language teaching in Indonesia, regional vernaculars are at the school level that is observed in each region as the sustainable development of the course. The province of Yogyakarta for students, for instance, becomes multilingual such as Bahasa Indonesia and Vernacular (Javanese) language (Yulia, 2013). Therefore, communication by using the English language is not implemented by Indonesian students continuously in daily life. 
Educators in this condition are stakeholders who hold an important part in enhancing the schools' educational quality by the standard of the method to accomplish good criteria for graduates English language learners. Various obstacles are facing by the English language teacher. Communicative teaching of languages of English in the context again becomes troublesome teaching. According to Yulia (2013) that the framework of English language learning consists of numerous problems in terms of communicative methods; the competence level of the students, the scale of the class and available time, lack of consistent materials, speaking English practice, students' motivation of learning English. Those problems expressed that the factors of English language learning come from the internal and external sides.

The government of Indonesia emphasized the importance of the English language to be mastered by all Indonesian students. According to Lauder Lauder (2008) as cited in Crystal (2003), Huda (2000), and Jenkins (2003) there are various important roles of English as an International Language. The competence of English consists of broad benefits for some sectors, such as:

a. Economy and Business: the role of the foreign country as the only economy business in the world that offers some benefits for other foreign markets to join the marketplace. In fact, without using English, they can not do so. Therefore, Tourist in a particular industry is heavily dependent on the English language. Besides, any global corporation of foreign business offices must have workers that can communicate the English language.

b. International Relations: English is among the main languages that the United Nations and other primary foreign languages substances. Officials are allowed to learn and even practice the English language during their job working time, but when the English speaking language cannot be understood, English can be used as a language in the lingua Franca.

c. The Media: newspapers in countries around the world are posted in which a protected treatment is granted to English. Most of the US controls big advertising companies. Thus, English-language is used dominantly for Global programming on television and radio. English language films released for all fields of popular culture exclusively. The lyrics in English has entered artists, socio-political, literary status, and some musical events audiences worldwide:

d. Education: a significant majority of the scientific community, the papers were written are in English on all topics. English is mostly used more and more as a means of training in schools and colleges, including subject areas such as leadership, data technology, and the sciences that make unique technologies of English. English is also extensively taught for pupils which considering either a foreign language even more research in an English-speaking nation or as a region of an employment requirement.

e. Communication: a large part of the world counties speak in English. 80 percent stored data digitally from the universe in English. Furthermore, the Internet has made full of used online services without a clear understanding of the English language.

Learning motivation is needed by Indonesian students that consider English as the second language. Therefore, Indonesian learners must provide self-learning motivation to achieve some benefits of understanding the English language that can be used in some sectors filed.

\section{Learners' Learning Motivation}

Motivation is commonly defined as the propensity or ability of a learner to participate in or take the opportunity to accomplish a goal (Zhou, 2012). Motivation is a part of intrinsic factors that encourage learners to learn each task with the target of English language understanding. Besides, it creates a desire for the learners in facing each obstacle in the learning process. Thus, 
Children are less likely to collaborate, take some responsibility for them, or participate entirely in language learning without learning motivation.

Besides, Motivation as' procedures that can (a) encourage and activate behavior, (b) provide guidance or intention for action, (c) facilitate and encourage the behavior to develop, and (d) contribute to a specific behavior being chosen or desired (Yu \& Shu, 2017). Besides, Dornyei and Otto (1998) concluded that motivation as the continually combined arousal in a person who activates, guides, integrates, enhances, suspends, and assesses the cognitive and motor processes by choosing, optimizing, coordinating, and acting out the wishes or desire (successfully or unsuccessfully).

Zhou (2012) explained that motivation is accomplished in two forms in the language classroom. The first approach involves selecting the contents, practices, and materials that fulfil the learners' needs. Learners are more inspired to think of the approach to study the language is informative and worthwhile. The second way consists of building a classroom as an environment which gives confidence to learners. Therefore, the role of learning motivation in the English language both organization and instructor should be able to create a conducive learning environment. Besides, Slavin (2011) also agreed that class approaches that allow all kinds of students to succeed the certain information and awards students for community or a small team of learning activities. Furthermore, teacher-student and student-student increase the accomplishments or success of the whole community relationships of learners to be successful and cooperative learning.

In the context influences factors of learning, motivation enriches learners to learn the English language cooperatively. According to Slavin (2011) defined methods of instruction where teachers coordinate students in small numbers, which further cooperate to help each other to acquire learning materials. Methods of cooperative learning are studied extensively under some well-specified that are expected to significantly enhance student performance in most aspects and conditions. Coordinated types of cooperative learning have demonstrated success not only as commonly used but also for casual forms.

Adapted from(Slavin (1995), a clear path model of cooperative learning processes is diagrammed below. The particular performance relationships among the major theoretical relationships are defined by the cooperative learning approaches.

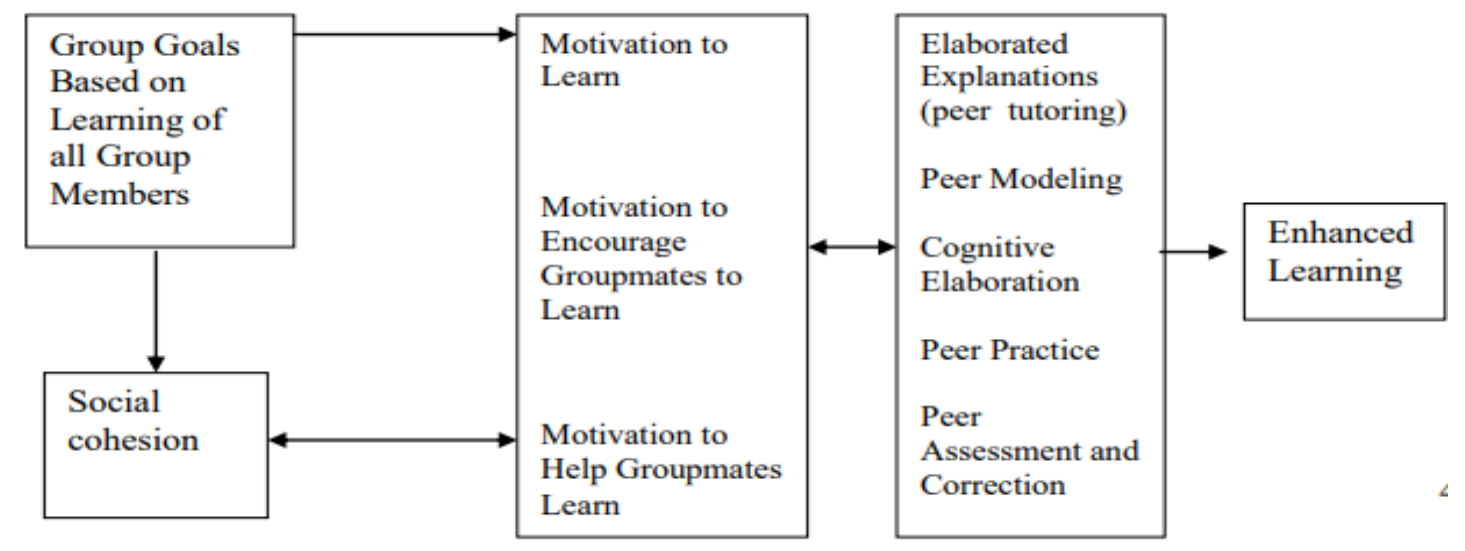

Figure 1. Integration of Interpretations on Cooperative Effects of Learning 
Figure 1 concludes with a sense of group objectives or rewards that is depending on the member of education by all community. That is also as the theory assumes that learning and motivation can encourage others to succeed in collaborative behaviors in learning contribution. This will include both encouragements for the assignment and motivation to communicate in the community. In this framework, motivation contributes directly to learning and also influences the thoughts and actions to unit cohesion, which in turn increases the kinds of social interaction that generate learning improvement and academic performance. The interactions are constructed to be mutual; this development will contribute to the growth of group cohesion, as mission motivation leads to the development of group cohesion to strengthen and boost job motivation. The cognitive processes can become inherently satisfying and contributing to the improvement of enthusiasm for assignments and team cohesion.

\section{Motivation in Language Learning}

Motivation leads to a reason for the mixture of behavior, expectations, and ability of the learner to acquire skills in learning English as a second language. It is usually thought to be one of the key causes of achievement and language learning failures (Richards and Schmidt, 2010). They also claimed that there is a difference between integrative and instrumental motivation and between intrinsic motivation and extrinsic motivation:

a. Integrative motivation involves organizational responsibilities (defined by a characteristic eagerness to respect the member of the language community) and a readiness to value the language community members. It is also the helpful orientation towards more practical issues such as getting a job, passing an exam, having a good attitude towards the native speakers both a dedication to learning the language, culture, and the language classroom.

b. Some other commonly cited difference is between intrinsic motivation and pleasure of learning language and extrinsic motivation on their own, determined by external factors such as family tension, predictions of society, grade standards, or other source materials of sanctions and incentives Richards and Schmidt (2010).

Besides, motivation can be defined to be a mixture of willingness and determination to obtain the purpose and optimistic attitudes toward it. Guerro (2015) researched that the two differentiated relationships between motivation and success rate in foreign language learning motivation, such as integrative that are focused on the willingness to become a part of this community of greater worth. Then, instrumental that is focused on the objective of successful work participation and social acceptance.

Motivation is such a theory that consists of the main psychological of people. One main point of intrinsic motivation is the process that comes from the people themselves. Therefore, intrinsic motivation is a basic need for English language learners. Teachers must be able to bring intrinsic motivation in the classroom learning situation (Long, Ming, and Chen, 2013) as cited Paul, Eggen, Kauchak, and Don, 2005). Besides, intrinsic motivation is necessary and important for the process of integration by which components of one's internal functionality information are accessible and integrated with scientific discoveries (Mahadi and Jafari, 2012).

While extrinsic motivation is the willingness to keep practicing the activities until the finish. Additionally, the students do the activity is because of to have present of gift to be given. Students tend to have extrinsic motivation is influenced by action practice. Generally, students in the ages of elementary and junior high school tend to have both intrinsic and extrinsic motivation, but extrinsic motivation is dominant. Thohir (2017) claimed extrinsic motivation is 
an external form of motivation. It provides a person with some factors, such as rewards achievement, pressure from society, and discipline.

Even if the motivation is among the best ways to enhance success in the learning of foreign languages, strategies to motivate nonnative speakers are seen as an important part of the theoretical aspect. Second-language observational (L2) motivation is also necessary, for example, to know where motivation comes from students. Teachers should become conscious of the references' motivation because they will have to know and act accordingly with their students (Buendía and Martín (2018). According to Madrid et al., (1993) that the students' sources of motivation would then rely on several variables, but they will depend on several variables. It relies primarily on birth, cultural and social history, family economic status, friends, interests, and more. Here are the factors varieties of motivation:

a. Methodology for the classroom: activities, duties, etc.

b. Qualities of the EFL teachers.

c. Parents and backgrounds in the family.

d. English as a concern for the school.

e. The willingness to incorporate into cultures of English speaking.

f. In culture, the fundamental role of English

\section{Discussions}

English in Indonesia is a second language. Indonesian students consider the importance of English in some fields such as; economy, business, education, etc. Therefore the roles of English mastery must also be supported by an internal and external factor. Both factors are important but internal factors should complete firstly in the process of learning English. Motivation in learning English categorized as the internal factors of learning English as a foreign language. High motivation in learning English can make the English skills learning effectively.

There is some other category of learning motivation which is integrative and instrumental. English as a foreign language learners have different outcomes of self-learning motivation. It occurs based on some different factors, for example, learning methodology, teachers' competence, family background, culture, and intention in learning English. Those factors that create some differences outcome to students learning motivation. One student can perform the level of learning motivation differently from one students to another students. Furthermore, a student has learning motivation in English language field, but they have different level category in keeping and developing their motivation in learning English.

Learning motivation can be changed from one student in exactly time, and it can be compared the quality and effective motivation of one students in current time and previous time. Therefore, one basic duty of the students and teachers is keeping and developing the students' learning motivation continuously by giving support of learning to English students class.

\section{CONCLUSION}

English mastery cannot occur directly without any support. It needs a process to complete the competence of English practice both spoken and written. Understanding the English language comes differently from one person to another. It depends on how deep students intend to comprehend the English lesson. The intention is similar to motivation; therefore motivation is the basic thing that students should provide in the process of learning English. If students have completed motivation as one of the intrinsic factors in achieving the learning objections, they 
will achieve the learning purpose easily. On the other side, the motivation of students can be different from one motivation to the other one. Furthermore, students must complete and support some factors that can increase the learning motivation optimally, because motivation cannot come naturally.

\section{ACKNOWLEDGMENTS}

We would like to say thanks to Allah SWT for his goodness and mercy in finishing this article en titled learning motivation as the basic needs in improving English skills for non- EFL learners cooperatively. In the process of completing this article, the researchers got support from many relatives and families. Especially, we would like to appreciate and thank for my families' supports and prays till this article is published in the journal. Hopefully this article give some beneficial for some other researchers and readers in English education field. Furthermore, I hope the review information brings wide mindset for the readers' understanding.

\section{REFERENCES}

Bahous, R., Bacha, N., \& Nabhani, M. (2011). Motivating Students in the EFL Classroom: A Case Study of Perspectives. English Language Teaching, 4(3), 33-43. https://doi.org/10.5539/elt.v4n3p33

Buendía, C. J. M., \& Ortega-Martín, J. L. (2018). Motivation: A key issue in the EFL classroom. International Journal of Diversity in Organisations, Communities and Nations, 17(1), 27 43. https://doi.org/10.18848/1447-9532/cgp/v17i01/27-43

Dornyei, Z., \& Otto, I. (1998). Motivation in action: A process model of L2 motivation. In Working papers in applied linguistics (Vol. 4). Retrieved from http://eprints.nottingham.ac.uk/39/

Guerro, M. (2015). Motivation in Second Language Learning: A Historical Overview and Its Relevance in a Public High School in Pasto, Colombia. How, 22(1), 95-106. Retrieved from https://files.eric.ed.gov/fulltext/EJ1127944.pdf

Hanafi Syahrozi, Dewi Rochsantiningsih, E. I. P. H. E. (2018). Improving Students' Motivation in Learning English Using Movie Clip. English Education Journal, 1(1), 55-63. https://doi.org/10.12681/eadd/1834

Kung, F.-W. (2017). Teaching and Learning English as a Foreign Language. The Electronic Journal for English as a Second Language, 21(2), 1-16. https://doi.org/10.5430/ijelt.v5n2p57

Lauder, A. (2008). The Status and Function of English in Indonesia: a Review of Key Factors. Makara Human Behavior Studies in Asia, 12(1), 9-20. https://doi.org/10.7454/mssh.v12i1.128

Long, C., Ming, Z., \& Chen, L. (2013). The study of student motivation on English learning in Junior middle school -- A case study of No.5 middle school in Gejiu. English Language Teaching, 6(9), 136-145. https://doi.org/10.5539/elt.v6n9p136

Madrid, D., Robinson, B. J., Hidalgo Tenorio, E., Gomiz van Heteren, A., Verdejo, M. J., \& Ortega, J. L. (1993). Sources of motivation in the EFL classroom. Jornadas Internacionales de Lingüística Aplicada. Robert J Di Pietro IN MEMORIAM, 1(1), 1-17.

Mahadi, T. S. T., \& Jafari, S. M. (2012). Motivation, Its Types, and Its Impacts in Language Learning. International Journal of Business and Social Science, 3(24), 230-235. Retrieved from http://ijbssnet.com/journals/Vol_3_No_24_Special_Issue_December_2012/24.pdf

Masyhur. (2016). Influence of Motivation and Language Learning Environment on the Successfull EFL Learning. (2010), 88-104. 
Parker, S. T. (1979). : Mind in Society: The Development of Higher Psychological Processes . L. S. Vygotsky. In American Anthropologist (Vol. 81). https://doi.org/10.1525/aa.1979.81.4.02a00580

Richards, J. C., \& Schmidt, R. (2010). Longman Dictionary of Language Teaching \& Applied Linguistics. In Longman.

Slavin, R. E. (1995). Research on cooperative learning and achievement: What we know, what we need to know. In Contemporary Educational Psychology (Vol. 21). https://doi.org/10.1006/ceps.1996.0004

Slavin, R. E. (2011). Instruction Based on Cooperative Learning. In Handbook of Research on Learning and Instruction. https://doi.org/10.4324/9780203839089.ch17

Thohir, L. (2017). Motivation in a Foreign Language Teaching and Learning. Vision: Journal for Language and Foreign Language Learning, 6(1), 20-28. https://doi.org/10.21580/vjv6i11580

Yu, H., \& Shu, Z. (2017). A Study on the Influence of Motivation on Open University Students' Vocabulary Attrition. International Journal on Studies in English Language and Literature, 5(3), 1-4. https://doi.org/10.20431/2347-3134.0503001

Yulia, Y. (2013). Teaching challenges in Indonesia: Motivating students and teachers' classroom language. Indonesian Journal of Applied Linguistics, 3(1), 1-16. https://doi.org/10.17509/ijal.v3i1.186

Yulistianti, H. D. (2016). Enhancing Motivation in Learning English: Students in Primary School. Jurnal Edulingua |, 3(1).

Zhou, H. (2012). Enhancing Non-English Majors' EFL Motivation through Cooperative Learning. Procedia Environmental Sciences, 12(1), 1317-1323. https://doi.org/10.1016/j.proenv.2012.01.428 